\title{
EL MÉTODO DE LA CRÍTICA DEL GÉNERO EN EL ANTIGUO TESTAMENTO. HISTORIA DE SU DESARROLLO
}

\author{
Leandro Ariel Verdini \\ Pont. Univ. Cat. Argentina (Buenos Aires) \\ lav@uca.edu.ar
}

Resumen: En este artículo presentamos las etapas fundamentales de la historia del desarrollo metodológico de la "historia de los géneros literarios" o también llamada "crítica de las formas" en los estudios del Antiguo Testamento. Proponemos delimitar los avances y búsquedas de esta metodología en tres períodos. El primero de ellos presenta a Hermann Gunkel y sus primeros discípulos. Exponemos sus propuestas fundamentales para la aplicación de la crítica y los logros principales obtenidos. El segundo período está caracterizado por los primeros intentos de sistematización y por grandes autores que desarrollaron el método. El tercer período lo consideramos el momento de mayor cristalización en la metodología; se produjeron diferentes manuales y obras que simplificaban su enseñanza al gran público. Finalmente se introducen nuevas propuestas y principios de aplicación, fruto del desarrollo de otras convicciones científicas en los estudios del Antiguo Testamento, que enriquecieron el método y le exigen hoy sustanciales reformas.

Palabras clave: Crítica de las formas. Historia de los géneros. Contexto vital. Géneros literarios. Crítica de la redacción.

Abstract: In this article we present the fundamental stages of the history of methodological development of Gattungsgeschichte or also called "Form Criticism" in Old Testament studies. We propose to delimit the advances and searches of this methodology in three periods. The first of them pre- 
sents Hermann Gunkel and his first disciples. We expose its fundamental proposals for the application of criticism and the main achievements obtained. The second period is characterized by the first attempts of systematization and by great authors who developed the method. The third period we consider the moment of greatest crystallization in the methodology; different manuals and works were produced that simplified its teaching to the public. Finally, new proposals and principles of application are introduced, fruit of the development of other scientific convictions in the studies of the Old Testament, that enriched the method and today demand substantial reforms.

Keywords: Form Criticism. History of the Genres. Sitz im Leben. Literary Genres. Redaction Criticism.

La historia de los géneros (Gattungsgeschichte) o crítica de las formas, según la nomenclatura que reciba a lo largo de su desarrollo, significó una inmensa posibilidad para los estudios bíblicos. La interpretación de los textos encontró un cauce para poder desarrollar las potencialidades de cada texto y explicar los interrogantes que nos plantean, y que en muchos casos distanciaba a no pocos creyentes de los avances de la modernidad o del diálogo con las ciencias, y hasta a veces alejaba del sentido común. En el siguiente artículo nos proponemos presentar la historia fundamental del desarrollo de esta herramienta metodológica que ya tiene más de un siglo de aplicación. Plantearemos cuatro etapas, según los cambios fundamentales realizados en el planteo de su aplicación metodológica. Dejamos fuera los acercamientos o enriquecimientos provenientes de la hermenéutica o de los acercamientos sincrónicos. La etapa final o nuevo paradigma nos dejará algunos interrogantes que cada lector deberá intentar responderse.

\section{Breve historia: de sus orígenes a su consumación}

\subsection{El padre de la crítica del género y sus primeros seguidores}

El comienzo de este instrumento que revolucionó la exégesis moderna denominado crítica de las formas o de los géneros nos pone frente al legado de Hermann Gunkel (1862-1932). Los tres pioneros de la crítica en el ámbito de estudios del Nuevo Testamento: Martin Dibelius (1919), Karl 
Ludwig Schmidt (1919) y Rudolf Bultmann (1921), se formaron sentados a los pies de Gunkel (1894-1907).

La intuición analítica de Gunkel comenzó en su comentario sobre el Génesis (1901), se profundizó en el comentario sobre los Salmos (1929) y se coronó en su introducción a los Salmos (1933), publicado después de su muerte ${ }^{1}$.

El trabajo de los Salmos lo continúo su alumno Sigmund Mowinckel, quien siempre reconoció la deuda con su maestro ${ }^{2}$. En los textos narrativos y proféticos fue Hugo Gressmann quien recogió y aplicó su legado ${ }^{3}$.

El padre de la crítica de la forma en realidad nunca quiso esta denominación, tampoco acuñó el término. Para él, el punto principal no eran las "formas" y su historia, sino una "historia de la literatura" que organizara el material acorde a los "géneros". En una carta enviada a su colega Adolf Jülicher (1925), él se distancia expresamente del lenguaje y la formulación de la cuestión, tal como la plantearon sus alumnos de NT; en concreto decía: "La palabra 'crítica de la forma' es especialmente incómoda para mí" 4 . Gunkel se interesó en estudiar lo abstracto de un texto, el patrón individual que trasciende su formación, es decir, el género 5. No le interesaban los aspectos concretos y particulares del texto, que es lo que la crítica suele designar como su forma.

A pesar de que planteaba la crítica en términos de "historia de la literatura”, es decir, de los géneros, para él era necesario liberarse del peso que generaba la historia. En su comentario al Génesis planteaba la necesidad de no comprender los relatos del libro de modo histórico. Por eso fue difícil para él la vida académica: muchos reconocidos expertos de Göttingen no querían su habilitación. Gunkel reconocía una gran cantidad de relatos orales que luego fueron escritos y fundidos en un solo relato histórico. Pero desvalorizaba el valor que contenían y, por tanto, era escéptico con la posibilidad de reconstruir la historia.

Gunkel comprendía los géneros como una coincidencia de textos, bíblicos en primer término, pero extrabíblicos también, que, como fruto de su comparación, expresaban puntos afines:

- pensamiento y sentimientos característicos,

- léxico común y características sintácticas símiles,

1 Cf. Gunkel, Genesis, ${ }^{81969 ;}$ ID., Die Psalmen, ${ }^{51968 ; ~ I D ., ~ E i n l e i t u n g ~ i n ~ d i e ~ P s a l m e n, ~}$ ${ }^{2} 1966$ (Introducción a los Salmos, 1983).

2 Mowinckel, The Psalms in Israel's Worship, 1962 (original noruego, 1951).

3 Gressmann, Die Schriften des Alten Testaments, ${ }^{2} 1921$.

${ }^{4}$ Rollmann, “Zwei Briefe Gunkel”, 283. En este caso estaba hablando concretamente de M. Dibelius.

5 Ibid., 284. 
- una conexión tradicional con la vida humana, especialmente en el ámbito social (Sitz im Leben).

Entendía como crucial la conexión de los géneros con la vida; aquel interés dio a su obra un elenco sociológico. "Si nosotros deseamos mirar la vida interior de los salmistas, debemos comenzar por estos tipos" ${ }^{\text {. }}$ El estado de ánimo, como categoría psicológica, también fue significativo para él, colocado como parte del contenido junto al pensamiento. El Sitz im Leben implicaba la búsqueda por comprender la medida en que una situación histórica resultó significativa para los autores bíblicos, a qué tipo de problema se respondía o "qué efecto tiene como objetivo"7. Gunkel propone las primeras preguntas que pueden dar la clave de esa situación: "¿Quién es el que habla? ¿Quiénes son los oyentes? ¿Qué sentimientos dominan la situación? ¿Qué efectos se pretenden?"8

\subsection{La segunda etapa de autores}

La segunda oleada de estudios, con la influencia de los estudios neotestamentarios, comenzó a hablar más de formas que de géneros. Profundizaron el estudio con la búsqueda de las fases orales y las tradiciones "perdidas", o más bien "presentes" pero ocultas en los textos. El primero, Albrecht Alt, reconoce a Gunkel como el fundador de la crítica de la forma $(\mathrm{CF})$, pero completa su programa con un famoso ensayo en el que se planteó el origen de Israel ${ }^{9}$. El interés de Alt fue transmitido a dos famosos exegetas: Gerard von Rad y Martin Noth.

Von Rad atribuye el marco y estructura del Hexateuco (Gn-Jos) a los tres credos históricos del temprano Israe ${ }^{10}$. Noth estudió lo que él llamaba el origen remoto del Pentateuco ${ }^{11}$. Él presume el origen de "temas básicos" en el ritual confesional del culto de Israel. El autor era consciente de la dificultad que implicaba el conocimiento de la tradición preliteraria u oral. Pero, a pesar de eso, afirmaba que el crecimiento y

${ }^{6}$ Gunkel, What Remains of the Old Testament and other essays, 1928, 62.

7 Ib., 62.

8 GUNKEL, “Die Grundprobleme”, en Reden und Aufsätze, 1913, 33.

9 ALT, “Der Begründer der gattungsgeschichtlichen Forschung in der alttestamentlichen Wissenschaft"; “Die Ursprünge des israelitischen Rechts”, en Kleine Schriften, vol. I, 1934, 285 n1.

10 “El problema morfogenético del Hexateuco", en Von RAD, Estudios, 1976, 11-80 (original alemán, 1938).

11 Noтн, A History of Pentateuchal Traditions, 1972 (original alemán, 1948). 
configuración de la tradición fue la etapa más creativa de la historia del Pentateuco $^{12}$.

La sistematización de la CF en el AT fue realizada por un antiguo alumno de Von Rad, Klaus Koch. Realizó el primer manual de la materia recogiendo los aportes de las dos generaciones previas de autores ${ }^{13}$. El universo de la CF seguía en el ámbito histórico. La crítica exigía la separación de unidades literarias de su contexto, pero el procedimiento, para él, era una investigación histórica. El manual tuvo un pobre desarrollo, no era la síntesis esperada para recoger el método y acercarlo a los investigadores; solo se quedó en simples introducciones ${ }^{14}$.

Vale la pena destacar una breve síntesis, con la claridad típica de su legado, que realizó Luis Alonso Schökel en un artículo publicado en 1960. Con un perfecto latín buscó acercar a las lenguas romances los aportes de Gunkel y de la crítica de los géneros ${ }^{15}$. También finalizado el Concilio Vaticano II profundizó para todo el mundo católico de habla hispana el acercamiento a la teoría y metodología de la crítica de los géneros en todo un capítulo del comentario que realiza a la Dei Verbum ${ }^{16}$.

\subsection{Tercera etapa: la cristalización del método}

La tercera oleada de estudio se caracterizó por el intento de sistematizar el legado de las dos generaciones anteriores. Los críticos comenzaron a reconsiderar el verdadero legado de la CF y las posibilidades que brindaba -a pesar de sus limitaciones- para comprender el AT.

En lengua germánica, con la publicación de su obra metodológica en 1971, Wolfgang Richter romperá con el proceso tradicional de la crítica ${ }^{17}$. Propone una orientación estructuralista para el estudio crítico de la Biblia. Para comprender su modo de trabajar con la CF hay que comprender una primera distinción. La forma la entiende como un texto único o individual, mientras que el género lo considera como "un tipo de texto", un número de

12 Cf. ib., 44-47.

${ }_{13} \mathrm{KoCH}$, The growth of the biblical tradition, 21969 (original alemán, 1964).

14 Cf. Campbell, "Form Criticism's Future”, en Sweeney - Ben Zvi, The Changing Face, 2003, 21.

15 Alonso Schökel, “Genera literaria”, VD 38.

16 Alonso SchöKel, “Hermenéutica racional: los géneros literarios”, en Comentario a la Constitución, 433-480.

17 RICHTER, Exegese als Literaturwissenschaft, 1971. 
textos comparables entre sí por su similitud o elementos estructurales idénticos. La CF deja de tener, para él, un desarrollo diacrónico para pasar a estudiarse de modo sincrónico. Para Richter se debe disponer la unidad a analizar en su grado original con la ayuda del análisis de las fuentes o crítica literaria, que aportará los grados de composición de un texto; si no será imposible aplicar la CF. Existe una dependencia metodológica de una con la otra.

La CF reduce su investigación al estudio del texto individual en su condición sincrónica final, según lo aportado por la crítica literaria. Mientras, tradicionalmente, la Formgeschichte procedió principalmente de forma diacrónica (como historia de los géneros o de las formas), él la comprenderá sincrónicamente. En este punto radica la diferencia más importante de su aporte y la distinción de Richter con la escuela tradicional de la CF. Él propone un concepto personal de género distinto del de Gunkel.

1) Es una realidad puramente formal, no de contenido.

2) Se opone a la forma, que es individual, mientras que el género es típico; la forma es concreta, el género es abstracto; el género equivale a una estructura de reglas formales.

3) Para abstraer el género se ha de excluir el criterio de historicidad (relación con el referente), la categoría de los protagonistas, las categorías de otras literaturas (sagas, leyendas).

4) Determinante de un género es la estructura repetida, o sea, la estructura común a varios individuos, común en determinado grado de abstracción; también puede caracterizar un género algún grupo de estilemas.

5) A un género puede pertenecer una unidad completa en sí, un miembro disgregado, un fragmento incompleto.

6) A un género pertenecen solo unidades independientes entre sí; se excluye el principio imitación, o sea, el valor generativo de una obra ejemplar; en caso de independencia podemos hablar de la historia de una forma, no de un género ${ }^{18}$.

Es fundamental la claridad metodológica y terminológica que Richter ofrece ${ }^{19}$. El peso es puesto, como dijimos, sobre el análisis estructural

18 Este elenco lo tomamos de la presentación que hace AlONSO ScHöKEL de la obra de Richter en un artículo publicado en 1972: "Sobre el estudio literario del Antiguo Testamento", en Hermeneutica II, 248-249.

19 El proceso de su análisis metodológico se puede observar con rigurosidad en el artículo de Rechenmacher - Van der Merve, "The Contibution of Wolfgang Richter". 
de la forma. Divide la crítica en el análisis de la forma y en el de su función. El análisis de la forma implica: a) los ornamentos (sonido, ritmo y rima), y $b$ ) la forma estructural en sus dos dimensiones: $b .1$ ) exterior (la sintaxis sobre las oraciones y palabras, y la estadística de las mismas) y b.2) interior (la estructura profunda de la unidad). Esta última dimensión interior es de importancia trascendental para él, pues es indicativa de los campos semánticos de las palabras o de los grupos de ellas, de la posición y movimientos de las mismas en el texto. Por último, el análisis de la función lo desarrolla a partir de la cuestión del propósito de la unidad y el alcance que sus contenidos pueden tener más allá de la forma. La CF, tal como la comprende Richter, presupone la gramática hebrea y una base lingüística para la misma ${ }^{20}$.

En los estudios de lengua alemana, la vasta propuesta de Richter será continuada por el suizo Odil Steck, quién conservará en su exitoso manual metodológico un fuerte énfasis de presentación lingüística, lo que sugiere, entre otras cosas, un análisis intensivo de las palabras y frases clave, y que pueden ofrecer enlaces a las ideas convencionales ${ }^{21}$.

Fue muy importante en Latinoamérica un manual de métodos exegéticos desarrollado desde Argentina por un grupo de prestigiosos exegetas de la escuela del recordado Instituto Superior de Educación Teológica ${ }^{22}$. A pesar de que el manual tardó un tiempo en llegar, sin duda llenó un vacío importantísimo en la lengua española, pues comenzó a acercar a los estudiantes de temas bíblicos, desde nuestra lengua, a la crítica del género y de la forma.

En lengua inglesa cabe resaltar un manual ${ }^{23}$ y un estudio ${ }^{24}$ que comenzaron a delinear el camino fecundo que recorrerían durante varios años los profesores de la Escuela de Teología de Claremont, California. Ellos delinearon un método más sofisticado y rigurosamente ensayado en los textos del AT. El propósito fue una serie de comentarios llamados FOTL (The

20 El autor es consciente de ello, por eso consagró sus años al desarrollo de los estudios lingüísticos y gramaticales: Grundlagen einer althebräischen Grammatik. I. Das Wort (Morphologie), 1978; II. Die Wortfügung (Morphosyntax), 1979; III. Der Satz (Satztheorie), 1980.

21 STEck, Old Testament Exegesis, ${ }^{2}$ 1998. El manual fue traducido por James Nogalski en 1993 a partir de la 13a edición alemana; la primera versión data de 1971.

22 Croatto, "Crítica de los géneros y las formas del AT", en Krüger - Croatto - MíGUEZ, Métodos, 1996, 161-187.

23 TuCKER, Form Criticism, 1971. Probablemente el manual de referencia con más aceptación en los últimos cuarenta años y utilizado como texto base por varias generaciones para el aprendizaje de la crítica.

${ }^{24}$ KNIERIM, “Old Testament Form”. 
Forms of the Old Testament Literature) y editados por Eerdmans. El proyecto comienza a planificarse a fines de la década del sesenta, pero recién en 1981 se publicó la primera obra, continuándose hasta la actualidad ${ }^{25}$. Fue el modo de especificar una nueva etapa de trabajo científico y, a nuestro juicio, el acontecimiento más fecundo para la CF en el AT. El texto siguiente pertenece al prólogo que hacen los primeros editores de la colección (Rolf Knierim y Gene Tucker) en el primer volumen de la misma:

El inicio de esta serie es el resultado de las deliberaciones y planes que comenzó hace unos quince años. En ese momento, los editores actuales percibieron la necesidad de una obra de referencia integral que permita a los estudiosos y estudiantes de las Escrituras hebreas que se benefician de los conocimientos que había acumulado el trabajo de crítica de la forma a lo largo de siete décadas, y al mismo tiempo para participar ellos mismos más efectivamente en dicho trabajo. Un equipo internacional e interconfesional fue creado, y se ha ampliado en los últimos años ${ }^{26}$.

Las observaciones que había formulado Knierim en su artículo respecto a la necesidad de estudiar primero las estructuras en las que aparecen inmersas las formas antes que las tipificaciones propias de cada género fueron asumidas desde el comienzo en la serie por los comentaristas de FOTL.

La crítica de las formas se ha interesado en las estructuras típicas, y en general ha tendido a relegar la interpretación de la singularidad de los textos a la exégesis posterior. Ahora bien, parece necesario revertir este enfoque: no solo el análisis estructural de la individualidad de los textos debe estar incluido dentro del método de crítica de la forma, sino que, de hecho, este debe preceder al análisis de la estructura típica (del género); sobre todo si la aseveración muestra que una tipicidad determina inherentemente un texto individual, esto debe ser justificado ${ }^{27}$.

Cada interpretación de un texto comienza con la presentación de la estructura del texto en forma esquemática. Sigue el debate que proporciona la estructura, junto con el intento de distinguir en esta lo típico de los elementos individuales o únicos que posee y los procedimientos para la determinación del género, su entorno y su intención. Los factores de tradición histórica se van discutiendo a lo largo de este proceso. Sobre todo la posible evidencia de la existencia de una fase escrita u oral del material antes del texto escrito final.

${ }^{25}$ El actual editor de la colección, Marvin Sweeney, me confió personalmente que con el volumen 19 de la serie, dedicado a ls 40-66, de su propia autoría, se finaliza la colección, que ya no volverá a publicar ningún otro volumen.

${ }^{26}$ Murphy, Wisdom Literature, 1981, ix.

27 KNIERIM, “Old Testament Form”, 461. 
Los lineamientos de la colección ponen el énfasis en la situación redaccional final de los textos, asumiendo así los aportes de la Redaktionsgeschichte a la crítica bíblica del AT que se habían instalado en la exégesis; sobre todo a partir de las consideraciones de Von Rad sobre Génesis y de Noth sobre la Historia deuteronomista ${ }^{28}$.

A diferencia de la mayoría del trabajo tradicional de la crítica de la forma, la interpretación de los textos partía de la premisa fundamental de que los poseemos en su etapa de escritura más reciente tal como se encuentran; técnicamente hablando, en la fase de su redacción final. Por tanto, cualquier acceso a estos debe confrontar y analizar esta última edición.

En consecuencia, el comentario procede desde el análisis del corpus literario más grande desarrollado por las redacciones que vuelven a las etapas anteriores discernibles en su historia literaria. Se examinan en primer lugar las unidades más grandes y luego sus subsecciones. Por tanto, en la mayoría de los casos, la primera unidad en ser examinada en términos de estructura, género, ambiente e intención es todo el libro bíblico del que se trate; el comentario siguiente trata las unidades individuales más grandes y más pequeñas a continuación ${ }^{29}$.

\section{Nuevos paradigmas de la crítica}

\subsection{Del "autor" al "lector supuesto"}

Una de las prácticas clásicas del método es el problema del ambiente en el que se originaron los textos y que requiere un ejercicio de reconstrucción especulativa. La tendencia entre los comentarios de la serie FOTL es desenfatizar las cuestiones de redacción histórica hasta cierto punto, en el que se favorece preferentemente la atención a los libros en su forma final. Tomó en esta línea un giro más radical en la serie el comentario sobre Miqueas, de Ehud Ben Zvi ${ }^{30}$, quien hizo de este principio en su aplicación una reforma fundamental al método de la CF en todo su comentario. Él se niega firmemente a especular con formas y ambientes de tradiciones anteriores usadas por los tradentes de Miqueas en su libro; incluso critica a las escuelas que intentan reconstruir estadios tempranos en la formación del libro:

\footnotetext{
28 Cf. $A B D$, “Redaction Criticism”, V, 644.

29 Murphy, Wisdom, x.

30 Ben Zvi, Micah, 2000.
} 
Uno puede notar, en pocas palabras, que estos acercamientos tienden a poner su atención sobre un conjunto de posibles, pero todavía especulativas, reconstrucciones de las palabras del Miqueas histórico; estas reconstrucciones son el logro principal de eliminaciones selectivas del texto presente sobre las bases de 1) percepción de reglas de estilo, consistencia temática, y 2) un acercamiento al texto que presupone que su versión original debe haber sido compatible con un alto grado de correspondencia entre el mundo del texto y el de el Judá monárquico del siglo vIII ${ }^{31}$.

En el comentario de Miqueas, y también en el posterior de Oseas ${ }^{32}$, él muestra cómo las acusaciones de los textos proféticos podrían pertenecer a una imagen de la realidad que no necesariamente puede corresponderse con un tiempo determinado. Son ficciones que se producen en todo tiempo. Los textos no dejan marcadores que señalen un proceso histórico concreto. Las denuncias de Mi y Os pueden pertenecer a cualquier período temporal.

Roy Melugin presenta la revisión que hace Ben Zvi de la CF, y one en evidencia cómo en el nuevo siglo se comenzó a perder el interés por la historia de la redacción, o más bien se continúa, pero de un modo más limitado y menos especulativo. "Debemos aprender a dejar a la función poética con su propio registro de referencialidad, ya no artificialmente al servicio de la referencialidad histórica exclusivamente" 33 . Este concepto, Melugin lo había puesto en evidencia en un artículo anterior hablando sobre algunos textos poéticos de Isaías:

La mayor parte de lo que el libro de Isaías representa, sin embargo, es difícil de correlacionar con precisión con los acontecimientos históricos reales. Leemos acerca de las hijas de Sión “cuyo brillo elegante será reemplazado por la peor ropa confeccionada" $(3,16-4,1)$, pero no sabemos casi nada acerca de los acontecimientos históricos particulares que podrían haber ocasionado este enunciado. Escuchamos una canción sobre Israel y los hijos de Judá, quienes juzgan la viña de Yhwh debido a la incapacidad para hacer justicia (5,1-7), pero nada sabemos de las circunstancias específicas que pueden haber ocasionado esta canción. Debido a que estas representaciones son metafóricas, no sabemos si son eventos específicos generados por ellos o si son descripciones de un comportamiento característico formulado de modo metafórico. El lenguaje del texto es una barrera para la resolución precisa de tales incertidumbres ${ }^{34}$.

31 lb., 25.

32 Su segunda obra en la edición, en donde se asumen los mismos lineamientos de trabajo que en el anterior; cf. Ben Zvi, Oseas, 2005, 21.

33 Melugin, "Recent Form Criticism Revisited in a Age of Reader Response", en The Changing Face, 57.

34 Melugin, "Prophetic Books and the Problem of Historical Reconstruction", en 
Melugin plantea entonces la necesidad de redescubrir lo convencional (como opuesto a lo históricamente particular), ambientes en los que el registro típico de dichos fueron habitualmente empleados; pero como en muchas ocasiones no disponemos de suficiente información para recuperar el ambiente, no debemos proceder "en el nuevo siglo otorgando una excesiva prioridad a algo que es en la práctica frecuentemente incapaz de realización exitosa". Se debe dar menos énfasis a la reconstrucción del ambiente fuera del texto y "mirar más cómo el texto despista de la realidad a la que se refiere" ${ }^{35}$.

Ben Zvi se preocupa de comprender la actividad de los lectores que está supuesta en la obra. El contrato que los redactores realizan con ellos de leer y releer todo un libro escrito. Él sostiene que los lectores de los libros de Miqueas y de Oseas fueron leyendo el libro como un texto posmonárquico, escrito para un auditorio del período posexílico. En la mímesis del texto es retratado un mundo monárquico debido a la información histórica que contienen los títulos (Mi 1,1 y Os 1,1), pero, a pesar de esto, los lectores actuales del libro pertenecen a una situación diferente, caracterizada por la realidad del posexilio. Esta diferencia entre el mundo del texto y el de los lectores les exige que usen el libro para hablar y comprender su situación propia, un escenario que fue marcadamente diferente del mundo monárquico presentado en la letra del libro. Ellos podían leer, y seguramente lo hicieron, leyendo y releyendo la obra. El fruto que debe haber resultado, dice Ben Zvi, es una multiplicidad de lecturas, debido a la polivalencia del texto ${ }^{36}$.

En un estudio posterior con un grupo de autores cercanos a su pensamiento, Ben Zvi clarificó más todavía su modo de acercamiento a la profecía bíblica y, por añadidura, los rasgos de su aplicación metodológica. El interés por la lectura holística de la obra que se mostraba en sus comentarios ahora pasa a la comprensión de todo el canon. La propuesta formula un cambio de paradigma en la comprensión anterior de los libros bíblicos, que fraccionaba y agrupaba las tradiciones y el pensamiento aislando a sus redactores, pero que no contemplaba los modelos demostrados por los estudios históricos:

Los intelectuales historiadores se interesan por una determinada obra literaria y su trasfondo. Con frecuencia se comprometen en la reconstrucción de los discursos antiguos. Reconstruyen o intentan reconstruir el sistema o

Breck Reid, Prophets and Paradigms, 1996, 72.

35 Melugin, “Recent Form”, 57-58.

36 Cf. Ben Zvi, Micah, 5-10; ID., Hosea, 7-8. 
conjunto de ideas relacionados entre sí, las formas de pensar, los tejidos de imágenes, los recuerdos, los conocimientos comunes y los registros lingüísticos que dieron forma a: al cuestión o conjunto de cuestiones que fueron propensas a surgir en una comunidad; b) las formas en que la comunidad se dedicaba a pensar sobre estos temas cuando surgieron les decir, qué mapa de imágenes, memorias sociales y registros lingüísticos se activaron para hacer frente a estos temas), y c) no solo la gama de cuestiones, sino también la gama de posibles respuestas recibidas y las normas que rigen la interacción de las mismas dentro de la comunidad.

En nuestro campo ha habido una tendencia a centrarse en los libros o conjuntos de libros como si fueran mundos separados, cada uno en evolución sobre su propio camino y asociado a un grupo social distintivo que trabajó para mantener y desarrollar una tradición ideológica específica y, por encima de todo, una obra literaria particular que lo exprese. [...]

En otras palabras, estamos hablando de múltiples discursos separados, cada uno de los cuales nos ha dejado uno o muchos de los libros bíblicos. Pero ¿cuándo y dónde existían estos múltiples discursos separados? ¿Cuándo y dónde podrían haber existido estos múltiples discursos separados y sus correspondientes grupos sociales? ${ }^{37}$

Su conclusión es evidente: no se pueden separar los corpus bíblicos, aislarlos unos de otros, imaginando que no se conocían sus autores, que compartían mundos distintos o que polemizaban entre sí (Historia deuteronomista, Pentateuco, tradiciones isaianas o ezequielinas). Solo un pequeño grupo de escribas letrados de la provincia persa de Judea era el responsable de todos los escritos. Ellos crearon -dice- "sitios de memoria", que son visitados una y otra vez en la lectura, para recordar el pasado "autointerpretado", leído y releído en estos textos escritos ${ }^{38}$. Un discurso intelectual en el que solo los escribas letrados acceden a la palabra de Yhwh y, por concomitancia con el pensamiento del Señor y la memoria de Israel, que debe interpretarlos, como intermediarios del conocimiento divino.

Ellos se convierten en mediadores indispensables entre Yhwh, el proveedor del conocimiento, e Israel, que necesita de ese conocimiento para mantener sus caminos y cumplir con sus obligaciones a Yhwh. La metáfora de Yhwh como el Comunicador o el Maestro de Israel, que es fundamental en este discurso, refleja la propia construcción de los letrados como los maestros de Israel y los comunicadores del mensaje del Señor. Es fundamental y subyacente para toda la literatura profética ${ }^{39}$.

37 Ben Zvı, "Towards an Integrative Study of the Production of Authoritative Books in Ancient Israel", en Edelman - Ben Zvi, The Production, 2009, 15-16.

38 Cf. ib., 19.

${ }^{39} \mathrm{lb}$. 
Los escritores de los libros proféticos no fueron para él meros redactores o simples transcriptores inertes de oráculos dichos por otros. Ellos fueron expertos escritores que, al igual que otras escuelas teológicas del AT (la deuteronomista, la sacerdotal, la de los piadosos de los Salmos, los siervos isaianos o los grupos sapienciales), seleccionaron y reinterpretaron antiguas tradiciones para expresar su propio pensamiento y su voz. Ben Zvi sostiene que los libros proféticos fueron el intento de los escribas letrados de crear un tipo de monopolio sobre el "conocimiento divino" que solo ellos poseían. "La Palabra de Yhwh es un texto escrito al que solo los literati tienen acceso directo [...] En este mundo, los literati se convierten en mediadores entre Yhwh [...] e Israel, el cliente que necesita del conocimiento para mantener su camino y completar sus obligaciones con el patrón" 40 .

\section{Balance final}

El acento puesto en la composición final de los libros concentra el trabajo histórico en el grupo redaccional, al que Ben Zvi responsabiliza de toda la obra, y a la vez le obliga a correr el objetivo o la pregunta fundamental de la CF: ¿cómo leían este texto en el contexto del dominio persa? Quizá, por lo que respecta a la existencia de este grupo letrado de escribas, redactores de todos los corpus literarios, cabe preguntarse: ¿son suficientes las pruebas históricas para comprender al grupo tal como él lo plantea o especula dentro de una hipótesis imposible de demostrar, que es un espejismo de su propio mundo y que justamente es una práctica metódica criticada por él?

Los estudios históricos afirman actualmente que en la provincia persa de Yehud se podría pensar en unos 20.000 habitantes $^{41}$, y que en la ciudad de Jerusalén habría alrededor de 1.500 personas $^{42}$. De este número es mínima la cantidad poblacional que dominaba la escritura, quizá un $5 \%$ o, como máximo, un $10 \%$. El número de escribas que habitaban en la Jerusalén persa se estima entre 75 y 150. Parece posible entonces pensar que se

40 Ben Zvi, Micah, 11.

41 Cf. Carter, The Emergence, 1999, 246-248; 0. Lipschits, "Persian Period Finds", JHS 9 (20a) (2009) 3. Otros autores estiman incluso un número menor: 1.000 habitantes (cf. Geva, “Excavations at the Citadel of Jerusalem", en ID. [ed.], Ancient, 2000, 156-167), y los más minimalistas hablan de una base de entre 400 y 600 personas durante el siglo v (cf. ZWICKEL, “Jerusalem”, 2008, 216-217; FINKELSTEIN, “Jerusalem in the Persian", 2008, 501-507).

42 Cf. Carter, The Emergence, 201. 
conocieran las escuelas teológicas de escritores, que polemizaran, discutieran y que se planteara -de cara al pueblo- una lucha por el ejercicio del poder entre estos grupos.

Lo más notable del aporte de Ben Zvi y de su escuela exegética ${ }^{43}$ -tal como formulamos en el título- es el movimiento o cambio en la focalización. De centrarse antes principalmente en las intenciones de los autores, ellos pasan a prestar ahora más atención e interés a la actividad de los lectores directos del libro de la provincia de Yehud.

En los últimos años, la crítica literaria se ha concentrado sobre el rol de los lectores en la explicación del significado (cf. Wolfang Iser, Umberto Eco, Stanley Fish). Mientras los críticos no están todos de acuerdo en cuanto a la naturaleza y ampliación del rol del lector en su hacer el significado "lectorrespuesta", ellos realmente coinciden en que los lectores traen a la actividad de interpretación una influencia en un grado no pequeño respecto a cómo un texto será comprendido ${ }^{44}$.

Ben Zvi tiene la intención de reconstruir qué hacen los lectores en un período particular, el período persa II (entre el 450 y el 332 a. C.). El énfasis puesto en la polivalencia del texto y en la actividad de las relecturas complica la recuperación de lo que en ese período comprendieron en realidad los lectores. Melugin critica esta postura observando que esa propuesta parece incitarnos a imaginar una relectura desde nuestros días más que la practicada en ese tiempo por los israelitas. Ben Zvi parece imaginar a esos israelitas como lectores entrenados en el seguimiento de los signos linguiísticos del texto, en caminos análogos a los de nuestra crítica moderna, o quizá proyectando en ellos nuestros propios intereses. Sin duda, ellos podrían haber puesto atención al texto y a sus señales, pero seguramente no en el mismo camino que recorremos nosotros ${ }^{45}$.

Es cierto que desenfatizar un poco el intento de reconstrucción histórica o Sitz im Leben convencional tiene bastante sentido. No porque carezca de valor conocerlo, sino porque nuestras reconstrucciones son frecuentemente fruto de nuestras ciegas especulaciones.

El cambio desde una orientación principalmente histórica a una principalmente literaria no elimina totalmente las preguntas históricas que Gunkel y sus discípulos se hacían por el género y el ambiente. El desafío por delante se encuentra en lograr armonizar las dos orientaciones, sin per-

${ }^{43}$ Cabe distinguir un importante estudio histórico-teológico, en la misma línea de trabajo, realizado por Gerstenberger, Israel in the Persian Period, 2011 loriginal alemán, 2005).

44 Melugin, “Recent Form”, 59-60.

$45 \mathrm{lb} ., 60$. 
der la agudeza que brinda el conocimiento histórico del surgimiento de los textos (Sitz im Leben) y comprendiendo a la vez la lectura que realizaban los escribas tardíos de toda la composición en su estadio final, tal como los textos nos han llegado (Sitz im Buch).

\section{Bibliografía}

Alonso SchöKel, L., "Genera literaria”, VD 38 (1960) 3-15.

-, "Hermenéutica racional: los géneros literarios", en Comentario a la Constitución "Dei Verbum" sobre la divina revelación (BAC), Madrid 1969, 433-480.

-, "Sobre el estudio literario del Antiguo Testamento", en Hermenéutica de la Palabra II, Madrid 1987, 242-256.

Alt, A., Kleine Schriften zur Geschichte Des Volkes Israel, Leipzig 1934.

Ben ZvI, E., Micah (FOTL, vol. XXIB), Grand Rapids, MI, 2000.

-, Hosea (FOTL, vol. XXIA/1), Grand Rapids, MI, 2005.

Breck ReID, S., Prophets and Paradigms. Essays in Honor of Gene M. Tucker (JSOTSup 229), Sheffield 1996.

Buss, M., Biblical Form Criticism in its Context, Sheffield 1999.

Carter, C., The Emergence of Yehud in the Persian Period: A Social and Demographic Study (JSOTSup 29), Sheffield 1999.

Edelman, D. - Ben Zvi, E., The Production of Prophecy. Constructing Prophecy and Prophets in Yehud, London 2009.

Finkelstein, I., "Jerusalem in the Persian (and Early Hellenistic) Period and the Wall of Nehemiah", JSOT 32/4 (2008) 501-520.

Gerstenberger, E., Israel in the Persian Period: The Fifth and Fourth Centuries B.C.E., Atlanta 2011.

Geva, H. (ed.), Ancient Jerusalem Revealed, Jerusalem 2000.

Gressmann, H., Die älteste Geschichtsschreibung und Prophetie Israels (von Samuel bis Amos und Hosea), Göttingen ${ }^{2} 1921$.

Gunkel, H., Genesis, Göttingen ${ }^{8} 1969$.

-, "Die Grundprobleme der israelitischen Literaturgeschichte", en Reden und Aufsätze, Göttingen 1913, 29-38.

-, Introducción a los Salmos, Valencia 1983.

-, Die Psalmen, Göttingen ${ }^{5} 1968$.

-, What Remains of the Old Testament and other essays, London 1928.

Knierim, R., "Old Testament Form Criticism Reconsidered", Int 27 (1973) 435-68.

KосH, K., The growth of the biblical tradition: The form critical method, New York ${ }^{2} 1969$. 
Krüger, R. - Croatto, S. - Míguez, N., Métodos exegéticos, Buenos Aires 1996.

LiPschits, O., "Persian Period Finds From Jerusalem: Facts and Interpretations", JHS 9 (20a) (2009) 2-30.

Mowinckel, S., The Psalms in Israel's Worship, Oxford 1962.

MurPHY, R., Wisdom Literature (FOTL, vol. XIII), Grand Rapids, MI, 1981.

Noth, M., A History of Pentateuchal Traditions, Englewood Cliff 1972.

Rechenmacher, H. - VAn der Merve, C., "The Contribution of Wolfgang Richter to Current Developments in the Study of Biblical Hebrew", JSS L/1 (2005) 59-82.

RICHTER, W., Exegese als Literaturwissenschaft. Entwurfeiner alttestamentlichen Literatur Theorie und Methodologie, Göttingen 1971.

Rollmann, H., "Zwei Briefe Hermann Gunkel an Adolf Jülicher zur religionsgeschichtlichen und formgeschichtlichen Methode", ZTK 78 (1981) 276-288.

Steck, O., Old Testament Exegesis, Atlanta, GA, ${ }^{2} 1998$.

Sweeney, M. - Ben Zvi, E., The Changing Face of Form Criticism for the Twenty-First Century, Grand Rapids, MI, 2003.

Tucker, G., Form Criticism of the Old Testament, Philadelphia 1971.

Von RAD, G., Estudios sobre el Antiguo Testamento, Salamanca 1976.

Zwickel, W., "Jerusalem und Samaria zur Zeit Nehemias. Ein Vergleich", Biblische Zeitschrift 52 (2008) 201-222.

(recibido: 27/12/16 - aceptado: 03/04/17) 